\title{
Students' Perceptions of using Literary Genres to Enhance Language Proficiency
}

\section{Bazimaziki Gabriel}

Lecturer of Literature, University of Rwanda, Department of Humanities and Language Education, P.O Box 55 Rwamagana Rwanda

bazimazikigabrie1@yahoo.com

\begin{abstract}
In Rwanda, Literature in English is taught in higher education to enable University leavers not only be equipped with ethical values, critical thinking and analytical skills but also communication skills in English; a global language which has become a multipurpose communication tool especially in this century geared by information Technology in many if not all life domains. From Pre-primary to tertiary levels of education, English has been emphasised in Rwanda to enable its citizens be acquainted with it and be proficient in it so that they can communicate without many difficulties and integrate with the globalisation. While efforts have been made at all education levels, the English language proficiency issue is still rampant. At tertiary level, crosscutting courses such as EAP (English for Academic Purposes) and ESP (English for Specific Purposes) have been emphasised but they are not enough for students to be well equipped with enough communication skills in English. Subjects such as literature in English should complement the two subjects for learners to improve and enhance that language. This study aims to exploring the role that literary genres hold in that process. The researcher builds on the belief that literary genres can be used to enhance language communication skills, critical thinking and creativity in language learning as they expose learners to contexts that can enable them to use language in describing various things and situations, hence developing their communication competences. The study bears qualitative analysis and involved year two students enrolled in English and Literature Education discipline with particular interest in how their language has improved each through literary genres. It was found that most of the students underwent increase of language proficiency at various level each in the four language skills namely listening, speaking, writing and reading.
\end{abstract}

Keywords-English language, literary genres, literature in English, proficiency, fluency, language in higher education.

www.jiels.com

\section{BACKGROUND}

Language is a tool by which art is conveyed and the latter is in turn a tool trough which language can be improved. English language is significant now-days as it holds a pivotal part in human life. Its importance is perceived everywhere and includes, but is not limited to, being a global Lingua Franca, global language for Ecommunication and Education, dominant business language, international tourism and the internet language, social media or Multi-media industry language among other things (Richa, 2017). In Rwanda, While English is taught as a FL (Foreign Language) from primary to tertiary levels of education to enable its citizens be acquainted with it and be proficient in it so that they can communicate without many difficulties, literature in English is taught in higher education to enable University leavers not only be equipped with ethical values, critical thinking and analytical skills but also communication skills in English; a global language which has become a multipurpose communication tool especially in this century geared by Information Technology in many, if not all life domains. The fact that students leave secondary to university having difficulties of communication skills in English poses a number of questions and some blames are laid to trainers regardless of trainees whose contribution to their learning is of a great need. In my understanding, the strategies of improving English language should not undermine the use of particular literary genres because language teaching aims primarily at human communication in his social, cultural, economic and political experiences while, in the same vein, literary genres depict human beings in the world around them at the four mentioned levels. Research has it that literary genres expose learners to contexts that can force or enable them to use language in describing various things and situations, hence developing their communication competences. Similarly, people who study and use a language are mainly interested in how they can do things with language - how they can make meanings, get attention to their problems and interests, influence their friends and colleagues and create a 
social life for themselves (Collins, 1990; Van cited in Hadjoui\&Kheladi, 2014; Farrah\& Zahra, 2016). Literary texts can be used successfully in language content based instruction classes as they are an ideal and powerful tool to enhance the communicative skills of the language particularly because literary texts supply examples of authentic language, provide lots of opportunities for the expression of ideas, opinions, and beliefs. Literary exploration can be beneficial in the language classroom and learners of English as a Foreign Language are in the process of language development when they start reading and experiencing literature using language for a variety of communicative purposes (Shang, 2006; Maley, 2001; Divsar\&Tahriri, 2009; Noaman, 2013; Zyoud, 2010; Chen Zhen, 2012, Ellison, 2010; Khatib, 2011).

In this regard, be they prose, poetry, drama among others, literary genres give a room for personal expressions. These genres can help the teacher engage learners during the teaching and learning process by telling them to do things using language. For example, as long as learners are giving their views on story characters and themes affecting them, or discussing the story setting, they are actually developing their linguistic performance. Not surprisingly, telling stories among themselves or relating the situation in a story to their real life, learners are certainly developing their communication skills. It is against this background that I wanted to explore the use of literary genres to enhance language proficiency.

\section{AIMS AND RESEARCH QUESTIONS}

Literature deals not only with human experience but also communication through language. Through literary genres, language skills improve through interaction, reading, and writing. In academic sector where English is a medium of instruction, literary courses taught in English are an added advantage for learners to be well equipped with communication skills in it especially if it is a second language. A number of factors including learners' motivation and their interest in these literary courses affect such mastery in one way or another. Students in higher education in Rwanda are not exception. While they learn literature in English, they often leave studies for job market still grappling with language difficulties linked with how they were trained and how they behaved all along their studies. Among these futures job performers, my interest lays on Year two English and Literature Education students whose courses are mainly literary. Investigating in their perceptions of using literary genres to enhance language skills is necessary so as to know in what teachers' efforts can be made to cater for the English language issue among university leavers to be.

Thus, the purpose of this study is three fold. First, I was interested in having a look at the use of Literature to enhance language proficiency at tertiary education by throwing light on how students have improved their English Language proficiency through literary genres. I particularly wanted to look into learners' perceptions towards enhancing communication skills through literary genres. Another aim was to explore students' interest in literary modules, pinpoint students' challenges militating against these modules and how they can be mitigated to be proficient in English, a global and multipurpose language. Thus, the underlying aim for this research is to cogently look into the relevance of Literature as a tool to improving language skills. In line with these aim, the study will seek answers to the following questions: (1) to what extent are university students interested in literary subjects? This question is congruent with the first aim. Following closely, the second aim matches the questionabout (2) how students have improved their language through literary genres. Lastly, seeking answer to the questions(3) What are the challenges do students encounter in their learning literary courses " and how can these challenges be mitigated to enhance language proficiency?" matches with the thirdaim of the study. From the above research questions stems an idea that literary genres can enhance learners' communication competences.

\section{Theoretical Framework}

The role of literature in language skills development is undeniable. Literature is the subject which, when not approached from a dogmatic perspective, opens space for an almost unlimited application of creative and critical thinking strategies (Pokrivčák, 2018). This paper is concerned with how Literature holds a pivotal role to enhance language proficiency. I basically traced back to Murthy et al. (2015) who view that reading; writing, speaking, listening and thinking are developed concurrently; hence should not be educated as separate topics. Inherently, any literary genre can fit for the development of these skills. Further, I concurwith Richards (2006) particularly his communicative language learning approach resulting from processes such as purposeful interaction between the learner and users of the language creating and negotiating meaning trying out and experimenting with different ways of saying things. The diagram below will serve for framework in this study. 


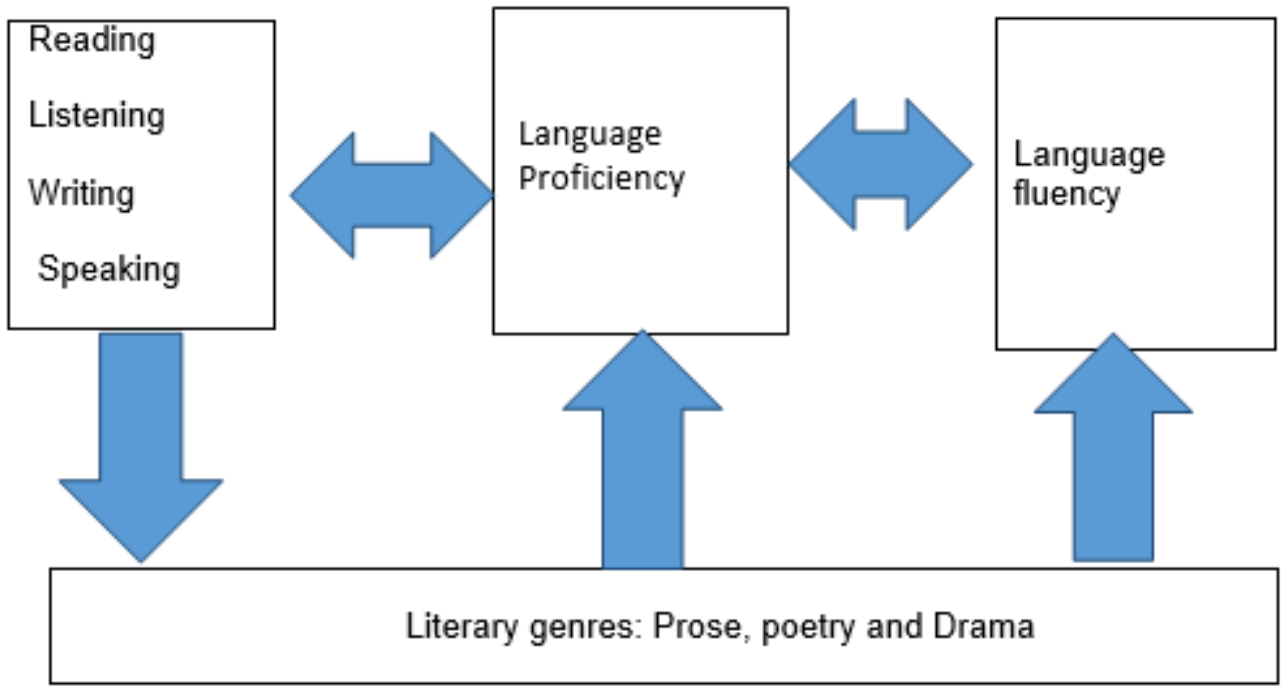

Note: The diagram above is my own conception.

Research put it that fluency and proficiency can overlap and depend on each other. Donavan (2018) opines that the term 'fluency' is reserved for a grade or spectrum for one's speed or smoothness of speech and posits that the term 'proficiency' strictly refers to one's ability to use a language. Fluency of a language, put another way, consists of its mastery based on the four skills such as the ability to read what is written in that language, write, speak or produce and comprehend the speeches delivered in it. Being proficient in a given language entails having less advanced skills in the use of a language, less easily and at a lessadvanced level than a native speaker of that language. Most noteworthy, the concern in this study is English language proficiency but not fluency simply because participants in this study are not native but foreign speakers and learners of English language.

Generally, the main literary genres are prose, poetry and drama which have their types each. These reflect humans through language. How well one is fluent or proficient in it will affect their understanding of these literary genre and the more one is interested in them, the more s/he can improve their language proficiency or become more fluent in language in which these works of art are written. In other words, the foregoing diagram reflects the interface between the three elements holding a central part in this study namely literary genres which cannot be disconnected totally from language skills; language proficiency and fluency. Literature and language are tools to each other and the improvement of language skills will depend on how the learners use the two henceany of the three main literary genres can fit for the four skills mentioned above.
Quoted in Yavuz (2010), Lazar(1993) advocates that literature is a motivating and authentic teaching tool embodying general educational value and helps students to understand another culture, develops students' interpretive abilities, expands students' language awareness and encourage them to talk about their opinions and feelings. Divsar and Tahriri (2009) put it that EFL (English as a Foreign Language) learners are in the process of language development when they start reading and experiencing literature. For example, poetry is used to develop these skills because when children recite the same poem, listen to the same fairy-tale, sing the same song, they will enjoy drawing the same picture and laugh at the way grammarcan be learned (Stakanova and Tolstikhina, 2014) a view echoed in (Panavelil, 2011; Finch, 2003 and Taplin, 2015) who opine that teaching poems enlivens the class and enriches learners vocabulary through creativity while promoting their personal communication skills.

Following closely, as types of prose, short stories help students to improve the four language skills-listening, speaking, reading and writing-- more effectively because of the motivational benefit embedded in the stories. Stories can bring pleasure to students' lives and their potential as tools in the teaching and learning process. Murdoch (2002) says that short stories provide quality text content that can be used to enhance learners' language proficiency. Concurrently, Lao and Krashen (2000) rank short stories powerful teaching materials that can serve to improve learners' vocabulary and reading. According to Farrah \& Zahra, (2016) the use of short stories benefit learners in that such genres enhance their language skills, motivate them and develop their personal reflections while creating 
cultural tolerance among them an idea supported in NurayOkumus (2016) and then emphasized in Farrah \& Abu Zahra, 2016) that literature can be used as a positive stimulation to motivate students, and a good means to improve reading and writing skills; Ellis on (2010) echoed similar view when he asserted that stories are didactic tools in foreign language teaching as they develop positive attitudes to language learning, different cultures, self and others; naturally expose learners to foreign language in context, lexis, grammar, discourse and pronunciation through patterns and repetitions in the narrative. Besides, novels serve as a tool through which EFL learners can not only develop their language skills but also serve as window through which they can perceive the target culture, learning how native speakers think, communicate and live (Chihhsin, 2012).

Notwithstanding the role of prose and poetry, drama cannot be left out and in the view of Nawi (2014), creative drama can be an interesting and motivating tool to enhance language as it provides students with opportunity to use both verbal and non- verbal communication thus helping learners to develop both drama skills and language skills concomitantly. Through drama, more so, a class will address, practice and integrate reading, writing, speaking and listening. Drama can foster and maintain students' motivation, reading, writing, speaking and listening skills by creating a suitable context for language learning and enables learners to interact/communicate with others using their stored language (Davies, 1990).Drama pedagogies increase motivation and competency in English language learning. (Elkaya, 2005; Nawi, 2014; Zyoud, 2010; Davies, 1990). Despite sizeable researches in that contention, not much attention was paid to students' perceptions of improving learners' language proficiency through literary courses. It is against all this background that I wanted to investigate into the role of literary genres and students' language development in higher education.

\section{METHODOLOGY}

This study is concerned with students' perceptions on how literary genres contribute to their language skills improvement. The researcher bases on the assumption that learning literary subjects engages learners and enables them to interact, think critically and develop various language skills. The study is designed in qualitative analysis. Basically, qualitative method was used as dictated by the three research objectives. The study population consist of year two students following English and Literature with Education in University of Rwanda, College of Education. I used judgement sampling simply because they are much concerned with literary subjects. Thus, the choice of participants in this study was motivated by the researcher's background and area of interest in teaching Literature in English. More importantly, Ilker et al. (2016) explain that the rationale behind purposive sampling is to concentrate on people with particular characteristics who will better be able to assist with the relevant research. Data were collected using two questionnaire completed by six students at the completion of one literary course titled 'Novel and Short Story'.

\section{PRESENTATION AND DISCUSSION OF RESULTS}

Information generated from respondents based on questionnaire with four main themes concerning literature in English and how it effects the students' language proficiency. These themes are presented as follows: Students' interest in literary genres, language skills they improved through these genres of interest, learning activities that can be more focused in literature to help learners improve their language, challenges militating against this improvement and how they can be mitigated. Following these themes, students' views are presented as follows:

For the first theme, majority of respondents, five over six $(83 \%)$ said that they are interested in prose and poetry and confirmed that these genres of interest helped them improve their language. Respondents revealed that poetry helped them be equipped with literary devices by which they discovered new terms thus improved their vocabulary. For the second theme concerning language skills that students have improved through literary genres, four respondents (66.6\%) said that they improved their reading and speaking skills through group discussions with classmates, one (16.6\%) improved writing through assignments; while another (16.6\%) improved listening skills by listening carefully to colleagues during presentation of works assigned. As regard the third theme concerned with the learning activity that should be more focused in literary courses, four students (66.6\%) revealed that classroom presentations should have enough room to enable them improve their speaking skills. Two students (33.3\%) said that classroom literary analysis can be more focused to enhance language use. For the fourth theme concerned with challenges students enrolled in literary disciplines face, all students $(100 \%)$ converge on a number of difficulties such as insufficiency of literary books recommended in their courses or modules description; little time devoted to reading; and the internet resource related problem. To cater for these challenges, respondents suggested remedies which 
call teachers' efforts and learners' role play. Majority of respondents, i.e four over six $(66.6 \%)$ suggested that literature teachers should inspire and encourage their learners to like reading and provide them with enough time for reading. They reveal that teachers should be promoting the culture of reading among their students by assigning a lot of reading works. In the same line, students suggested an advocacy as regard the lack or shortage of literary books which match the courses. Concerning the role that students in literary disciplines should play to cope with challenges affecting them in the process of language skills enhancement, all respondents $(100 \%)$ revealed that students should enhance the culture of reading and share among themselves what they have read so as to develop the speaking and listening skills. Two students (33.3\%) added that reading from the physical library should be supplemented by doing research on internet. One(16.6\%) says that "students have to read more and more books avoiding weaknesses and search for other books which are missing in the library online[....]" while another believes that " developing the culture of research and communication with the others, these are major things that the students can do to improve their language skills. Because in these ways, reading, speaking, writing and listening will developed and improved (sick) effectively".

From all these respondents' views, it is clear that literature holds a pivotal role in language improvement. Actually, when one is interested in what they learn, it bears fruits. As most of students confirmed that they are very much interested in prose and poetry, these resulted in language skills improvement as they all confirmed when asked: Did this/these literary genre(s) help you improve your English Language skills?". It follows that most of respondents agree that their reading and speaking skills were improved through literary assignments. Of course, when assigned reading, they often time work either individually or in group where they interact and tell each other what they discovered and hence become well informed because "A reading nation is an informed nation". This promotes discussion and as such they can improve speaking skills not only when doing the works but also when they are presenting it before the class. Naturally, as "practice makes perfect", when students read for assignments, present what they have come up with, they improve three skills concurrently. From what they have read, they are now striving to jot down some ideas, hence developing their writing skills, and during presentation time speaking is developing gradually.

In the same light, when asked about the classroom activity that they think can be more focused during literature classes to help them improve their language skills, majority i.e four students $(66.6 \%)$ revealed that classroom presentation (of works done either individually or in group) outweighs the rest of learning activities in that they benefit a lot from it in terms of communication skills in particular. As for challenges they face in their learning literary courses, insufficiency or lack of books fitting their module descriptions, novels recommended in particular, coupled with little time devoted to reading and the problem of network, all slow down their motivation to reading. To cater for these challenges, respondents involve two parts among those concerned with the teaching and learning exercise to be carried out successfully. Teachers of literary subjects are called to cultivate into their students the culture of reading by telling them again and again the advantages of reading for a literary student. Of course, if encouraged and mobilised, learners will in the end know that literature without reading is like a mansion built without a strong foundation. They would be told that reading is an important exercise as it removes educational barriers, allowing more equal chances in education by promoting language development, intellectual training and enhancing the possibility of adjustment to one's personal situations (Ilori \&Abdullahi, 2016). Still in the same line, respondents revealed that students' role cannot be undermined in the exercise of promoting the culture of reading not only literary books but also any documents that can benefit them in terms of vocabulary enrichment. Respondents added that research based learning must be promoted by students themselves in a bid to improve language skills. One of the suggested solutions to cope with the challenges impeding language skills enhancement through literary genres goes with students' commitment to doing a lot of practice of writing and speaking exercises basing on what they already read and know.

\section{CONCLUSION}

Literature in English is taught in higher education in Rwanda to enable University leavers not only be equipped with ethical values, critical thinking and analytical skills but also communication skills in English. This study explored students' perceptions of using literary genres to enhance language proficiency. The study involved six learners enrolled in year two in the English and Literature Education class. Their perceptions revealed that literary subjects have helped them to enhance their language each. They suggested that teachers of literature focus much more on reading for classroom presentation so that they (students) can continue to develop their language skills concurrently. It was also suggested that students be committed to avoiding the culture of not reading since a "reading nation 
is an informed nation". Based on analys is of respondents' views, the assumption that learning literary subjects engage learners and enables them to interact, think critically and develop various language skills was confirmed. Notwithstanding the foregoing results as shown in this study, the author believes that these are the perceptions of a small class. Tobridge the possible gaps herein, the author suggests that a study of the same kind be carried out using bigger classes; or in the same pool; a study exploring the role of Drama to enhance students' language proficiency in higher education.

\section{REFERENCES}

[1] Chen Zhen (2012) Characteristics and strategies of Literature teaching in the EFL context in China. International Journal of Electronics and Communication Engineering. 5 (3), pp. 35-43

[2] Chih-hsin Tsai (2012) Students' perceptions of using a novel as main material in the EFL reading course in English Language Teaching. Canadian Center of Science and Education. Vol. 5, No. 8; 2012 ISSN 1916-4742 E-ISSN 1916-4750 Online Retrieved from http://dx.doi.org/10.5539/elt.v5n 8p103

[3] Davies, Paul (1990)The Use of Drama in English Language Teaching. TESL Canada Journal, 8(1).

[4] Divsar, H. \& Tahriri, A. (2009). Investigating the effectiveness of an integrated approach to teaching literature in an EFK context. Journalof Pan-Pacific Association of Applied Linguistics, 13(2), 105-116.

[5] Donovan Nagel (2018) The simple difference between language fluency and proficiency. On line. Retrieved from https://www.mezzoguild.com/fluencyproficiency

[6] Ellison Maria (2010) Make them think! Using literature in the primary English language classroom to develop critical thinking skills. Universidade do Porto.

[7] ErkayaOdilea Rocha (2003) Benefits of using short stories in the EFL context' in 'Asian EFL Journal: The EFL Professional's Written Forum. Retrived fromhttps://www.asian-efl-journal.com/.../benefits-ofusing-short-stories-in-the-efl-context.

[8] Farrah, Mohammed A. \& Abu Zahra, N., A. (2016) Using Short stories in EFL classroom.IUG Journal of Humanities Research. 24(1). 11- 24 pp.

[9] Finch, A. (2003) Using poems to teach English. English Language Teaching. 15(2), 29 -45. Retrived from https://www.researchgate.net/publication.
[10] Hadjoui Ghoutil\&Kheladi Mohammed (2014) Towards an Integrative Approach to Teaching Literature in an EFL Context inInternational Journal of Research inHumanities, Arts and Literature (IJRHAL)ISSN (E): 2321-8878; ISSN (P): 23474564Vol. 2, Is sue 4, Apr 2014, 113-126.

[11] IlkerEtikan, SulaimanAbubakar Musa, RukayyaSunusiAlkassim (2016). Comparison of Convenience Sampling and Purposive Sampling. American Journal of Theoretical and Applied Statistics. (5)1, pp. 1-4. doi: 10.11648/j.ajtas.20160501.11

[12] Ilori Maria Edeole and AbdullahiMosturaAdejoke (2016)Promoting reading habit among Secondary School Students in Lagos State: The role of Library and ICT. Asian Journal of Education and e-learning. 04(05) pp.145-152.

[13] Khatib Mohammed (2011) Literature in EFL/ESL Classroom. Canadian Center of Science and Education, available from www.ccsenet.org/elt English Language Teaching. 4(1) Retrieved on 31 November 2015 at 2: $00 \mathrm{pm}$.

[14] Lazar, G. (1993). Literature and Language Teaching: A Guide for Teachers and Trainers. Cambridge:CUP.

[15] Lao, C. Y.\&Krashen, S. (2000).The impact of popular literature study on literacy development in EFL: More evidence for the power of reading. System, 28, 261270.

[16] Maley, A. (2001) Literature in the Language Classroom. In R. Carter, and D. Nunan,The Cambridge Guide to Teaching English to Speakers of Other Languages. Cambridge: CUP.

[17] Mason, L. (2006). Mixing methods in a qualitatively driven way. Qualitative Research, 6(1),9-25.

[18] Murthy, Palavarapu Krishna \& Ram Raghu M.V.(2015) integrated approach to English language teaching in L2 classroom: a conceptual framework. Journal of English Language and Literature. Retrieved fromjoell.in/wp-content/.../2015/.../IntegratedApproach-to-English-Language-Teaching.

[19] Nawi, A. M. (2014). Using Applied Drama in English Language Learning. University of Canterbury, New Zealand (PhD Thesis).

[20] Noaman, Nabil N. (2013) Literature and the language skill.Al-ustath. 204(2).

[21] NurayOkumu, Ceylan (2016) ' Using short stories in reading skills class' in 'International Conference on Teaching and Learning English as an Additional Language, Glob ELT 2016, 14-17 April 2016, 
Antalya, Turkey. Procedia - Social and Behavioral

Sciences 232 (2016) 311 - 315.

[22] Panavelil, A. (2011) Teaching Poetry in an EFL/ESL Class:An Integrative and Communicative Approach. ELT Voices, India. ISSN 2230 - 9136.

[23] Pokrivčák, Anton (Ed.) (2018)Return to the Text. University of Trnava. ISBN 978-80-568-0149-9

[24] RichaTripathi (2017) Empowering English Language Teaching-Learning Process in India. International Journal of English Literature and Social Sciences (IJELS) Vol-2, Issue-6, Nov - Dec, 2017.https://dx.doi.org/10.24001/ijels.2.6.8 ISSN: 2456-7620.

[25] Shang, H. (2006). Content-based instruction in the EFL Literature Curriculum. The Internet TESL Journal, Vol.XII, 11.

[26] Taplin, Lysette(2015) Poetry and the ESL classroom: how rhyme can work for your students. ELT. OUP. Available fromhttps://oupeltglobalblog.com/2015/04/01/poetryin-the-elt-clas sroom/.

[27] Tumwebaze, P. (Ed.) (2015) Francophone to Anglophone: Is Rwanda on the right track. In New Times, 22 ${ }^{\text {nd }}$ July 2015.

[28] YavuzAysun (2010) Enhancing creativity in the communicative language classroom through poetry as a literary genre.DilDergisi 149 Temmuz-Ă̆ustos-Eylül

[29] Zyoud, Munther (2010). Using Drama Activities and Techniques to Foster Teaching English as a Foreign Language: a Theoretical Perspective. Retrieved from https://www.researchgate.net/publication/. 